\title{
RESEARCH
}

Open Access

\section{Effect of endophytic isolates of Beauveria bassiana (Balsamo) Vuillemin and Metarhizium anisopliae (Metchnikoff) Sorokin on Plutella xylostella (L.) (Lepidoptera: Plutellidae) in cabbage}

Poornesha Bathina ${ }^{1,2^{*}}$ and Ramanujam Bonam ${ }^{1}$

\begin{abstract}
Background: The diamondback moth (Plutella xylostella L.) (Lepidoptera: Plutellidae) is one of the major pests in cabbage which causes severe loss to the cruciferous crops. Entomopathogenic fungi Beauveria bassiana and Metarhizium anisopliae have been established as endophytes in cabbage plants by seed treatment/root inoculation/ foliar application methods in glasshouse conditions.

Main body: A glasshouse experiment was conducted to study the effect of endophytic isolates of $B$. bassiana (NBAIR Bb-5a and NBAIR Bb-45) and M. anisopliae (NBAIR Ma-4 and NBAIR Ma-35) on P. xylostella in cabbage using detached leaf bioassay method. The isolates were applied through seed treatment/root inoculation/foliar application at the concentration of $1 \times 10^{8}$ spores $/ \mathrm{ml}$ and evaluated at $15,30,45$, and 60 days after treatment (DAT) in 2017 and 2018. These isolates were colonized in cabbage leaf tissues from 15 to 60 DAT. All 4 isolates showed different mortality percentages during 15-30 DAT, and no mortality was observed after 45 and 60 DAT in different inoculation methods during both years. Among the application methods tested, foliar application method gave the highest mortality of $70-80 \%$ at 15 DAT and $12-58 \%$ at 30 DAT mortality of 2nd instar larvae of P. xylostella in cabbage. Among the isolates tested, NBAIR Ma-35 showed the highest mortality (35-79\%) in all the 3 inoculation methods tested.
\end{abstract}

Conclusion: Endophytic isolates of B. bassiana and M. anisopliae suppressed the population of $P$. xylostella on cabbage leaves in three inoculation methods tested. Among all the methods tested, foliar application method showed highest mortality. These promising isolates have to be further tested under field conditions for management of $P$. xylostella in cabbage.

Keywords: Beauveria bassiana, Metarhizium anisopliae, Plutella xylostella, Cabbage, Endophytic

\footnotetext{
*Correspondence: poorniintbiotech@gmail.com

'Division of Germplasm, Conservation and Utilisation, ICAR-National Bureau

of Agricultural Insect Resources, Post Bag No. 2491, H.A. Farm Post, Bellary

Road, Bengaluru, Karnataka 560024, India

${ }^{2}$ Department of Biotechnology, Center for Post Graduate Studies, Jain

University, Jayanagar, Bengaluru, Karnataka 560011, India
}

(c) The Author(s). 2020 Open Access This article is licensed under a Creative Commons Attribution 4.0 International License, which permits use, sharing, adaptation, distribution and reproduction in any medium or format, as long as you give appropriate credit to the original author(s) and the source, provide a link to the Creative Commons licence, and indicate if changes were made. The images or other third party material in this article are included in the article's Creative Commons licence, unless indicated otherwise in a credit line to the material. If material is not included in the article's Creative Commons licence and your intended use is not permitted by statutory regulation or exceeds the permitted use, you will need to obtain permission directly from the copyright holder. To view a copy of this licence, visit http://creativecommons.org/licenses/by/4.0/. 


\section{Background}

Cabbage, Brassica oleracea var. capitata L., is one of the extensively cultivated cruciferous crops in the world. India is the second largest producer of cabbage cultivating in an area of 0.40 million ha with a production of 9.04 million ton and average productivity of 22.56 ton/ ha (Anonymous 2018). The diamondback moth, Plutella xylostella (L.) (Lepidoptera: Plutellidae) is one of the major pests in cabbage. Its larvae feed extensively on cabbage leaves leading to drying, defoliation, and stunting of cabbage heads (Gujar 1999). The chemical insecticides are being used for management of P. xylostella in cabbage for a long time. Resistance development in the pest species was reported against most of the chemical insecticides and to the Bt-based products (Sayyed et al. 2008). Considering this as a significant concern, there is a need for an alternative safe and ecofriendly pest control method.

Utilization of entomopathogenic fungi (EPF) is one of the alternative biological control methods which play a key role on sustainable pest management programs. Cost effectiveness, simple mass production procedure, and safety to non-target organism and to the environment are some of the advantages of using these as biocontrol agents (Charnley and Collins 2007; and Lacey 2016). Apart from this, recently EPF species have been reported to colonize the tissues of certain crop plants by artificially inoculation for pest management programs (Vega 2018). This novel method of establishing them as endophytes in crop plants will help to overcome the dry weather conditions by giving them better effectiveness against insect pests. Thus, endophytically established isolates of Beauveria bassiana, Metarhizium spp., Lecanicillium spp., and Isaria spp. showed effectiveness against various arthropod pests in different crops (Mantzoukas and Eliopoulos 2020).

In earlier studies, four indigenous isolates of EPF, $B$. bassiana (NBAIR Bb-5a and NBAIR Bb-45), and $M$. anisopliae (NBAIR Ma-4 and NBAIR Ma-35) were found effective against $P$. xylostella in the laboratory bioassay and were also established as endophytes in cabbage by artificial inoculation of conidial suspensions. Hence, the present study aimed to evaluate the EPF endophytically established isolates against P. xylostella in cabbage under glasshouse conditions.

\section{Materials and methods}

The glasshouse experiment was conducted using NBAIR Bb-5a and NBAIR Bb-45 isolates of B. bassiana and NBAIR Ma-4 and NBAIR Ma-35 isolates of $M$. anisopliae using detached leaf bioassay method. The experiment was carried out in 2017 and 2018 to check the efficacy of these isolates.

\section{Insect culture}

Second instar larvae of $P$. xylostella were obtained from mass production unit of ICAR-NBAIR, Bangalore, India, for this study.

\section{Fungal culture}

Fungal cultures were obtained from Entomofungal Repository of National Bureau of Agricultural Insect Resources (ICAR-NBAIR), Bangalore, which were isolated from different agro-climatic zones of India (Table 1). Each fungal culture was grown on Sabouraud's dextrose yeast extract broth (SDYB) medium (dextrose $20 \mathrm{~g}$, mycological peptone $10 \mathrm{~g}$, yeast extract $5 \mathrm{~g}$, in $1 \mathrm{l}$ of distilled water) for mass production of this fungus on broken rice. Four-day-old shaker culture was added to sterilized rice bag and incubated for 15 days at $26 \pm 1$ ${ }^{\circ} \mathrm{C}$. The conidiated rice was used for preparation of conidial suspension. The conidial suspension was prepared by suspending $1 \mathrm{~g}$ of 15 -day-old conidiated rice in sterile distilled water with $0.01 \%$ Tween 80 . The conidial suspension was filtrated through three layers of muslin cloth to get hyphal-free suspension. The conidial concentration in the suspension was adjusted to $1 \times 10^{8}$ spores/ml using Neubauer's improved hemocytometer.

\section{Pot culture studies}

Cabbage var. Unnati was used for pot culture studies. As per the protocols of Tefera and Vidal 2009 and Russo et al. 2015 with slight modifications, seed treatment was given by dipping the cabbage seeds in conidial suspension $\left(1 \times 10^{8}\right.$ conidia $\left./ \mathrm{ml}\right)$ of each isolate individually for $1 \mathrm{~h}$ and were later sown into the sterilized coir pith trays. The seeds were dipped in sterile water containing $0.01 \%$ Tween 80 as untreated control. For root inoculation method, roots of 30-days-old cabbage seedlings were dipped into the conidial suspension $\left(1 \times 10^{8}\right.$ conidia/ml) for $1 \mathrm{~h}$ and later transplanted into the pots containing sterile soil and untreated control plants were dipped in sterile water containing $0.01 \%$ Tween 80 (Tefera and Vidal 2009; Russo et al. 2015). In foliar application method, conidial suspension of each isolate (1 $\times 10^{8}$ conidia/ml) was sprayed on 30 -day-old plants using hand atomizer. Untreated control plants were sprayed with sterile water containing $0.01 \%$ Tween 80 . Completely randomized block design with 5 replications were maintained with 10 plants per replication for each isolate and for each method.

\section{Detached leaf bioassay}

As per the Qayyum et al. (2015) with slight modifications, the leaf samples treated with the isolates of $B$. bassiana, $M$. anisopliae and the untreated control were collected at 15,30,45, and 60 days after treatment for bioassay studies against $P$. xylostella. The leaf samples 
Table 1 Details of promising isolates of Beauveria bassiana and Metarhizium anisopliae

\begin{tabular}{llll}
\hline Isolate code & $\begin{array}{l}\text { NCBI } \\
\text { Genbank accession number }\end{array}$ & Source & Location \\
\hline NBAIR Bb5a & JF837134 & $\begin{array}{l}\text { Hypothenemus hampei } \\
\text { (Coffee berry borer) }\end{array}$ & Karnataka \\
NBAIR Bb45 & JF837094 & Rhizosphere Soil of Carrot & Tamil Nadu \\
NBAIR Ma-4 & JF837157 & Plocaederus ferrugineus (cashew stem borer) & Karnataka \\
NBAIR Ma-35 & JQ518481 & Soil (fallow lands) & Gujarat \\
\hline
\end{tabular}

were surface sterilized by sodium hypochlorite (1\%) for $3 \mathrm{~min}$ and then with ethanol (70\%) for $30 \mathrm{~s}$. The surface sterilized samples were then rinsed in sterile distilled water for three times and dried on sterile blotting paper for $3 \mathrm{~min}$ in a laminar flow. The surface sterilization was done to eliminate surface microbial contaminants on the leaf surface. Each of the surface sterilized leaf was placed in a sterile plastic container and 2nd instar larvae of $P$. xylostella were released. Five replications (10 larvae per replication) were maintained for each isolate and untreated control. Fresh surface sterilized leaves of each treatment were provided to the larvae at $24 \mathrm{~h}$ interval. Larval mortality was recorded for a period of 10 days at $24 \mathrm{~h}$ intervals. The percent mortality of the larvae was calculated after deducting the control mortality using Abbott's formula (Abbott's 1925).

$$
\text { Corrected } \% \text { mortality }=\left(1-\frac{\mathrm{n} \text { in T after treatment }}{\mathrm{n} \text { in Co after treatment }}\right) \times 100
$$

Where $: \mathrm{n}=$ Insect population, $\mathrm{T}=$ treated, $\mathrm{Co}=$ control

Statistical analysis was mainly carried out among the treatments to find out the significant differences. Data of mortality were subjected to the ANOVA (analysis of variance) by statistical analysis using SPSS software 20 version.

\section{Results and discussion Detached leaf bioassay}

All the 4 isolates showed different mortality percentages during 15-30 days after treatment (DAT) in different inoculation methods in both years (Tables 2, 3, and 4).

In seed treatment during 2017, the 4 isolates showed 10-38\% mortality of P. xylostella at 15 DAT and the mortality ranged between 20 and $44 \%$ by the 3 isolates (NBAIR Bb-45, Ma-4, and Ma-35) at 30 DAT. In 2018, the 3 isolates (NBAIR Bb-5a, Bb-45, and Ma-35) caused P. xylostella mortality between 28.9 and $48.9 \%$ at 15 DAT, while the 4 isolates showed $28-48 \%$ mortality during $30 \mathrm{DAT}$. When the average mortality rates of the 2 years were taken into consideration, NBAIR Bb-45 and NBAIR Ma-35 isolates showed the highest mortality rates of 40.1 and $42.4 \%$, respectively, at 15 and $30 \mathrm{DAT}$, while NBAIR Ma-4 and NBAIR Ma-35 showed a high mortality rate of $36 \%$ each.

In root inoculation method during 2017, the 2 isolates (NBAIR Ma-4 and NBAIR Ma-35) showed 12 and 30\% mortality rates of $P$. xylostella, respectively, at $15 \mathrm{DAT}$ while the mortality ranged between 18 and $50 \%$ by the 3 isolates (NBAIR Bb-45, Ma-4, and Ma-35) at 30 DAT. In 2018, 3 isolates (NBAIR Bb-45, Ma-4, and Ma-35) showed 20-50\% mortality rates of P. xylostella at 15 DAT, while NBAIR Bb-45 and NBAIR Ma-35 showed 10 and 20\% mortality rates, respectively at $30 \mathrm{DAT}$. When the mortality rates of the 2 years taken into consideration, NBAIR

Table 2 Effect of endophytically established isolates of Beauveria bassiana and Metarhizium anisopliae on Plutella xylostella in cabbage (seed treatment method)

\begin{tabular}{|c|c|c|c|c|c|c|}
\hline \multirow[t]{2}{*}{ Isolate } & \multicolumn{2}{|c|}{$\%$ mortality-2017 } & \multicolumn{2}{|c|}{$\%$ mortality-2018 } & \multicolumn{2}{|c|}{ Mean mortality of 2017 and 2018 (\%) } \\
\hline & 15DAT & 30DAT & 15DAT & 30DAT & 15DAT & 30DAT \\
\hline NBAIR Bb-5a & $26.0 \pm 5.09^{a}$ & $0.0 \pm 0.00^{c}$ & $28.9 \pm 5.66^{b}$ & $42.0 \pm 3.74^{a}$ & $27.4 \pm 5.22^{b}$ & $21.0 \pm 1.87^{b}$ \\
\hline NBAIRBb-45 & $38.0 \pm 3.74^{a}$ & $20.0 \pm 3.16^{b}$ & $42.2 \pm 4.17^{\mathrm{ab}}$ & $30.0 \pm 3.16^{b}$ & $40.1 \pm 3.18^{a}$ & $25.0 \pm 2.24^{b}$ \\
\hline NBAIRMa-4 & $10.0 \pm 3.16^{b}$ & $24.0 \pm 5.09^{b}$ & $0.0 \pm 0.00^{d}$ & $48.0 \pm 3.74^{a}$ & $5.0 \pm 9.64^{c}$ & $36.0 \pm 2.45^{\mathrm{a}}$ \\
\hline NBAIRMa-35 & $36.0 \pm 5.09^{a}$ & $44.0 \pm 5.09^{a}$ & $48.9 \pm 5.68^{a}$ & $28.0 \pm 3.74^{b}$ & $42.4 \pm 9.84^{a}$ & $36.0 \pm 4.0^{a}$ \\
\hline Control & $0.0 \pm 0.00^{c}$ & $0.0 \pm 0.00^{c}$ & $10.0 \pm 3.16^{c}$ & $0.0 \pm 0.00^{c}$ & $5.0 \pm 9.38^{c}$ & $0.0 \pm 0.00^{c}$ \\
\hline $\begin{array}{l}F \text { value } \\
\text { df }\end{array}$ & $\begin{array}{l}18.026 \\
4,20\end{array}$ & $\begin{array}{l}27.484 \\
4,20\end{array}$ & $\begin{array}{l}23.530 \\
4,20\end{array}$ & $\begin{array}{l}32.962 \\
4,20\end{array}$ & $\begin{array}{l}35.532 \\
4,20\end{array}$ & $\begin{array}{l}35.787 \\
4,20\end{array}$ \\
\hline $\operatorname{LSD}(P<0.01)$ & 15.456 & 13.886 & 17.655 & 13.258 & 11.849 & 9.732 \\
\hline
\end{tabular}

Values in columns followed by the different letter are significantly different with each other according to LSD $(P<0.01)$ 
Table 3 Effect of endophytically established isolates of Beauveria bassiana and Metarhizium anisopliae on Plutella xylostella in cabbage (root inoculation method)

\begin{tabular}{|c|c|c|c|c|c|c|}
\hline \multirow[t]{2}{*}{ Isolate } & \multicolumn{2}{|c|}{$\%$ mortality-2017 } & \multicolumn{2}{|c|}{$\%$ mortality-2018 } & \multicolumn{2}{|c|}{ Mean mortality of 2017 and 2018 (\%) } \\
\hline & 15DAT & 30DAT & 15DAT & 30DAT & 15DAT & 30DAT \\
\hline NBAIR Bb-5a & $0 \pm 0.00^{c}$ & $0 \pm 0.00^{d}$ & $0 \pm 0.00^{c}$ & $0 \pm 0.00^{c}$ & $0 \pm 0.00^{d}$ & $0 \pm 0.00^{c}$ \\
\hline NBAIR Bb-45 & $0 \pm 0.00^{c}$ & $18 \pm 3.74^{c}$ & $20 \pm 4.47^{b}$ & $10 \pm 0.00^{b}$ & $10 \pm 2.24^{b}$ & $23 \pm 1.87^{b}$ \\
\hline NBAIR Ma-4 & $12 \pm 2.00^{\mathrm{b}}$ & $32 \pm 5.83^{b}$ & $46 \pm 5.09^{\mathrm{a}}$ & $0 \pm 0.00^{c}$ & $35 \pm 3.32^{c}$ & $16 \pm 2.92^{b}$ \\
\hline NBAIR Ma-35 & $30 \pm 3.16^{a}$ & $50 \pm 3.16^{\mathrm{a}}$ & $50 \pm 4.47^{a}$ & $20 \pm 3.16^{\mathrm{a}}$ & $40 \pm 2.74^{a}$ & $35 \pm 2.74^{a}$ \\
\hline Control & $0 \pm 0.00^{c}$ & $0 \pm 0.00^{d}$ & $0 \pm 0.00^{c}$ & $0 \pm 0.00^{c}$ & $0 \pm 0.00^{d}$ & $0 \pm 0.00^{c}$ \\
\hline$F$ value & 61.714 & 39.828 & 44.030 & 40.000 & 68.766 & 53.333 \\
\hline$d f$ & 4,20 & 4,20 & 4,20 & 4,20 & 4,20 & 4,20 \\
\hline $\operatorname{LSD}(P<0.01)$ & 7.504 & 13.701 & 16.105 & 5.842 & 9.862 & 8.132 \\
\hline
\end{tabular}

Values in columns followed by the different letter are significantly different with each other according to LSD $(P<0.01)$

Ma-35 showed the highest mortality rate of 40 and 35\%, respectively, at 15 and $30 \mathrm{DAT}$.

In foliar application method, all the 4 isolates caused $72-78 \%$ mortality of P. xylostella at 15 DAT and 12$58 \%$ at 30 DAT. In 2018, the 4 four isolates recorded $75-80 \%$ mortality rate of $P$. xylostella at 15 DAT and $13.3-55.6 \%$ at $30 \mathrm{DAT}$. When the average mortality of 2 years was taken into consideration, NBAIR Ma-35 showed the highest mortality of $79 \%$ at 15 DAT and $56.8 \%$ at 30 DAT.

No mortality was observed at 45 and 60 DAT in all the inoculation methods. No mycosis was observed on the dead larvae in all methods. The dead larvae which their color turned to brown were considered for mortality.

Among the three methods tested, foliar application gave the highest mortality rate of $P$. xylostella. Among the isolates tested, NBAIR Ma-35 showed the highest mortality rate in all the inoculation methods tested.

EPF as endophytes are reported as biocontrol agents showing effective protection to host plants from pests. There are reports of significant pest reduction and plant damage in certain crops by endophytically established EPF (Mantzoukas and Eliopoulos 2020). Also, there are reports of poor performance of endophytic EPF due to complexity of these EPF insect-plant interactions (Powell et al. 2009; Akello and Sikora 2012; Clifton et al. 2018; and Jensen et al. 2019).

M. anisopliae when inoculated into the plants of Brassica napus through foliar spray showed $63.3 \%$ mortality of $P$. xylostella larvae after 4 weeks of endophytic establishment (Batta 2013). Gautam et al. 2016 reported nonsurvival of $P$. xylostella larvae on $B$. bassiana sprayed leaves, which were attributed to production of certain volatile compounds produced due to the interaction of $B$. bassaina with the host plant and no mycosis was observed on the dead larvae. In the present study also, no mycosis was observed on the dead larvae.

A fungal endophyte Acremonium alternatum, when applied to the roots of Brussels sprouts (Brassica oleracea var. gemmifera) reduced DBM larval feeding and its growth rate (Raps and Vidal 1998). In the present study on cabbage, $B$. bassiana and $M$. anisopliae isolates when

Table 4 Effect of endophytically established isolates of Beauveria bassiana and Metarhizium anisopliae on Plutella xylostella in cabbage (foliar application method)

\begin{tabular}{|c|c|c|c|c|c|c|}
\hline \multirow[t]{2}{*}{ Isolate } & \multicolumn{2}{|c|}{$\%$ mortality-2017 } & \multicolumn{2}{|c|}{$\%$ mortality-2018 } & \multicolumn{2}{|c|}{ Mean mortality of 2017 and 2018 (\%) } \\
\hline & 15DAT & 30DAT & 15DAT & 30DAT & 15DAT & 30DAT \\
\hline NBAIR Bb-5a & $76 \pm 4.0^{a}$ & $12 \pm 2.0^{\mathrm{d}}$ & $75.0 \pm 3.95^{a}$ & $13.3 \pm 2.22^{c}$ & $75.5 \pm 3.76^{a}$ & $12.7 \pm 1.29^{c}$ \\
\hline NBAIR Bb-45 & $72 \pm 3.74^{a}$ & $30 \pm 3.16^{c}$ & $77.5 \pm 2.5^{\mathrm{a}}$ & $37.8 \pm 5.68^{b}$ & $74.8 \pm 1.15^{\mathrm{a}}$ & $33.9 \pm 4.01^{b}$ \\
\hline NBAIR Ma-4 & $74 \pm 2.45^{a}$ & $42 \pm 3.74^{b}$ & $70.0 \pm 8.48^{a}$ & $48.9 \pm 4.46^{\mathrm{ab}}$ & $72.0 \pm 5.31^{a}$ & $45.5 \pm 2.71^{a}$ \\
\hline NBAIR Ma-35 & $78 \pm 5.83^{a}$ & $58 \pm 3.74^{a}$ & $80.0 \pm 3.06^{\mathrm{a}}$ & $55.6 \pm 3.53^{a}$ & $79.0 \pm 3.48^{a}$ & $56.8 \pm 1.96^{a}$ \\
\hline Control & $0 \pm 0.00^{b}$ & $0 \pm 0.00^{e}$ & $20.0 \pm 3.16^{b}$ & $10.0 \pm 3.16^{c}$ & $10.0 \pm 1.58^{b}$ & $5.0 \pm 1.58^{d}$ \\
\hline F value & 80.714 & 63.667 & 27.956 & 26.758 & 73.727 & 75.201 \\
\hline$d f$ & 4,20 & 4,20 & 4,20 & 4,20 & 4,20 & 4,20 \\
\hline $\operatorname{LSD}(P<0.01)$ & 14.310 & 12.932 & 19.513 & 16.597 & 12.638 & 10.293 \\
\hline
\end{tabular}

Values in columns followed by the different letter are significantly different with each other according to LSD $(P<0.01)$ 
applied through foliar spray, showed $72-80 \%$ mortality of $P$. xylostella larvae after 15 DAT indicating their efficacy. In earlier studies, extent of endophytic colonization of EPF in cabbage leaf was studied in seed treatment/root inoculation/foliar spray through plating technique and PCR studies which indicated a high percent colonization in foliar application. The highest mortality of $P$. xylostella larvae observed in these studies may be due to the highest colonization of these isolates in cabbage leaves during that period. The mortality rate is mainly dependent on the internal colonization of the fungus and production of secondary metabolites in crop plants (Gautam et al. 2016). The larval mortality was mainly depended on the application method of the fungus as endophytes in the crop plants (Qayyum et al. 2015). Qayyum et al. (2015) reported that, B. bassiana successfully established as endophyte by root dipping method compared to the other inoculation methods (injection, solid substrate, and direct foliar application) and found effective against Helicoverpa armigera in tomato plants. Endophytic colonization of $B$. bassiana in cotton by seed treatment showed negative effect on the aphid species, Aphis gossypii (Lopez and Sword 2015) and reduction in survival of Helicoverpa zea. Earlier results on colonization indicated higher colonization and longer persistence in cabbage by foliar application method compared to root inoculation and seed treatment methods which attributed the mortality of P. xylostella. No mortality was observed at 45 and $60 \mathrm{DAT}$, which may be due to less/no colonization of the fungus in the cabbage leaves in all the inoculation methods. Few reports showed mycosis on endophytic screening of insects' viz., Cosmopolites sordidus, H. zea, H. armigera, and Tuta absoluta (Vega 2018) whereas in the present study no mycosis was observed.

The negative effect of fungal endophytes on the survival and performance on insect herbivores may be due to production of secondary metabolites and superoxides, changes in the phytosterol profile of plants or by inducing an indirect systemic defense response in the plants leading to resistance in insect feeding (Hartley and Gange 2009; and White and Torres 2010). The secondary metabolites of the endophytic EPF in plant tissues with anti-feeding properties and insecticidal activity might have led to the pest suppression through antibiosis or feeding deterrence (Vega et al. 2008; and Gurulingappa et al. 2011). Fungal toxins like destruxins were reported to be produced by endophytic Metarhizium robertsii in cowpea (Golo et al. 2014) and M. brunneum in melon and potato (Garrido-Jurado et al. 2017). The exact mechanisms on the effect of endophytic EPF on the herbivorous insects are yet to be studied in detail.

\section{Conclusion}

Endophytically established isolates of B. bassiana and $M$. anisopliae suppressed $P$. xylostella on cabbage leaves in three methods tested. However, foliar application method showed highest larval mortality. These isolates have to be further tested under field conditions to confirm their efficacy against $P$. xylostella in cabbage.

\section{Abbreviations \\ NBAIR: National Bureau of Agricultural Insect Resources; NCBI: National Center for Biotechnology Information; Bb: Beauveria bassiana: \\ Ma: Metarhizium anisopliae; DAT: Days after treatment; \\ EPF: Entomopathogenic fungi; DBM: Diamond back moth; SDYB: Sabouraud's dextrose yeast extract broth; Bt: Bacillus thuringiensis}

\section{Acknowledgements}

The authors are thankful to the Director, ICAR-National Bureau of Agricultural Insect Resources, Bengaluru, Karnataka, India, for the constant support provided throughout the research work.

\section{Authors' contributions}

BP performed the experiments on bioassay and analyzed the data. The manuscript was prepared by BP and BR. All the authors read and approved the manuscript.

\section{Funding}

This work was not supported by any funding body.

\section{Availability of data and materials}

All data are available in the article and the materials used in this work are of high quality and grade.

\section{Ethics approval and consent to participate}

Not applicable

\section{Consent for publication}

Not applicable

\section{Competing interests}

The authors declare that they have no competing interests.

Received: 19 August 2020 Accepted: 20 November 2020

Published online: 27 November 2020

\section{References}

Abbott WS (1925) A method of computing effectiveness of insecticides. J Econ Entomol 18:263-265

Akello J, Sikora R (2012) Systemic acropedal influence of endophyte seed treatment on Acyrthosiphon pisum and Aphis fabae spring development and reproductive fitness. Biol Control 61:215-221

Anonymous (2018) Agricultural Statistics at a Glance

Batta YA (2013) Efficacy of endophytic and applied Metarhizium anisopliae (Metch.) Sorokin (Ascomycota: Hypocreales) against larvae of Plutella xylostella L. (Yponomeutidae: Lepidoptera) infesting Brassica napus plants. Crop Prot 44:128-134

Charnley AK, Collins SA (2007) Entomopathogenic Fungi and their role in pest control. In: Kubicek CP, Druzhininna IS (eds) Environmental and Microbial Relationships, vol 4. Springer, Cham, Switzerland, pp 159-187

Clifton EH, Jaronski ST, Coates BS, Hodgson EW, Gassmann AJ (2018) Effects of endophytic entomopathogenic fungi on soybean aphid and identification of Metarhizium isolates from agricultural fields. PLoS ONE 13:e0194815

Garrido-Jurado I, Resquín-Romero G, Amarilla SP, RíosMoreno A, Carrasco L, Quesada-Moraga E (2017) Transient endophytic colonization of melon plants by entomopathogenic fungi after foliar application for the control of Bemisia tabaci Gennadius (Hemiptera: Aleyrodidae). J Pest Sci 90:319-330

Gautam S, Mohankumar S, Kennedy JS (2016) Induced host plant resistance in cauliflower by Beauveria bassiana. J Entomol Zool Stud 4:476-482

Golo PS, Gardner DR, Grilley MM, Takemoto JY, Krasnoff SB, Pires MS, Fernandes EKK, Bittencourt VREP, Roberts DW (2014) Production of Destruxins from 
Metarhizium spp. fungi in artificial medium and in endophytically colonized cowpea plants. PLOS ONE 9:e104946

Gujar GT (1999) Farmers' fight against diamondback moth. Pestic World:64-65

Gurulingappa P, McGee PA, Sword GA (2011) Endophytic Lecanicillium lecanii and Beauveria bassiana reduce the survival and fecundity of Aphis gossypii following contact with conidia and secondary metabolites. Crop Prot 30(3): 349-353

Hartley SE, Gange AC (2009) The impacts of symbiotic fungi on insect herbivores: mutualism in a multitrophic context. Annu Rev Entomol 54:323-342

Jensen RE, Enkegaard A, Steenberg T (2019) Increased fecundity of Aphis fabae on Vicia faba plants following seed or leaf inoculation with the entomopathogenic fungus Beauveria bassiana. PLoS ONE 14:e0223616

Lacey LA (ed) (2016) Microbial Control of Insect and Mite Pests: From Theory to Practice. Academic Press, Cambridge, MA, USA

Lopez DC, Sword GA (2015) The endophytic fungal entomopathogens Beauveria bassiana and Purpureocillium lilacinum enhance the growth of cultivated cotton (Gossypium hirsutum) and negatively affect survival of the cotton bollworm (Helicoverpa zea). Biol Control 89:53-60

Mantzoukas S, Eliopoulos P (2020) Endophytic Entomopathogenic fungi: a valuable biological control tool against plant pests. Applied Science, Sl: Endophytic Entomopathogenic Fungi: New approach for controlling serious pests. Applied Science 10(1):370. https://doi.org/10.3390/app10010360

Powell WA, Klingeman WE, Ownley BH, Gwinn KD (2009) Evidence of endophytic Beauveria bassiana in seed-treated tomato plants acting as a systemic entomopathogen to larval Helicoverpa zea (Lepidoptera: Noctuidae). J Entomol Sci 44:391-396

Qayyum MA, Wakil W, Arif MJ, Sahi ST, Dunlap CA (2015) Infection of Helicoverpa armigera by endophytic Beauveria bassiana colonizing tomato plants. J Biol Control 90:200-207

Raps A, Vidal S (1998) In-direct effects of an unspecialized endophytic fungus on specialized plant-herbivorous insect interactions. Oecologia 114:541-547

Russo ML, Pelizza SA, Cabello MN, Stenglein SA, Scorsetti AC (2015) Endophytic colonization of tobacco, corn, wheat and soybeans by the fungal entomopathogen Beauveria bassiana (Ascomycota, Hypocreales). Biocont Sci Tech 25:475-480

Sayyed AH, Saeed S, Noor-UI-Ane M, Crickmore N (2008) Genetic, biochemical, and physiological characterization of spinosad resistance in Plutella xylostella (Lepidoptera: Plutellidae). J Econ Entomol 101:1658-1666

Tefera T, Vidal S (2009) Effect of inoculation method and plant growth medium on endophytic colonization of sorghum by the entomopathogenic fungus Beauveria bassiana. BioControl 54:663-669

Vega FE (2018) The use of fungal entomopathogens as endophytes in biological control: A review. Mycologia 110:4-30

Vega FE, Posada F, Aime MC, Pava-Ripoll M, Infante F, Rehner SA (2008) Entomopathogenic fungal endophytes. Biol Control 46:72-82

White JF, Torres MS (2010) Is plant endophyte mediated defensive mutualism the result of oxidative stress protection? Physiol plant 138:440-446

\section{Publisher's Note}

Springer Nature remains neutral with regard to jurisdictional claims in published maps and institutional affiliations.

\section{Submit your manuscript to a SpringerOpen ${ }^{\circ}$ journal and benefit from:}

- Convenient online submission

- Rigorous peer review

- Open access: articles freely available online

- High visibility within the field

- Retaining the copyright to your article

Submit your next manuscript at $\boldsymbol{\nabla}$ springeropen.com 